\title{
COMPARATIVO DA MATRIZ CURRICULAR DO CURSO EM LICENCIATURA EM QUÍMICA DO IFAP COM O CONTEÚDO DO ENADE
}

\section{ARTIGO ORIGINAL}

SANTOS, Lívia Maria Sousa dos ${ }^{1}$, TATY, Salvador Rodrigues², FERNANDES, Erlyson Farias $^{3}$, FECURY, Amanda Alves ${ }^{4}$, DENDASCK, Carla Viana 5 , OLIVEIRA, Euzébio de $^{6}$, DIAS, Claudio Alberto Gellis de Mattos ${ }^{7}$

SANTOS, Lívia Maria Sousa dos. Et al. Comparativo da matriz curricular do curso em licenciatura em química do IFAP com o conteúdo do ENADE. Revista Científica Multidisciplinar Núcleo do Conhecimento. Ano 06, Ed. 03, Vol. 14, pp. 2940. Março de 2021. ISSN: 2448-0959, Link de acesso: https://www.nucleodoconhecimento.com.br/educacao/matriz-curricular, $\quad$ DOI: 10.32749/nucleodoconhecimento.com.br/educacao/matriz-curricular

\section{RESUMO}

Matriz curricular é o conjunto de componentes curriculares (disciplinas) que garante o conteúdo necessário a formação de um discente em um curso e sofrem constantes alterações em razão da velocidade com que as inovações acadêmico-tecnológicas

\footnotetext{
${ }^{1}$ Estudante do Curso Técnico de Química (segundo grau) do Instituto de Ensino Básico, Técnico e Tecnológico do Amapá (IFAP).

${ }^{2}$ Químico, Mestre em Química (UFMA), Professor e pesquisador do Curso de Licenciatura em Química do Instituto de Ensino Básico, Técnico e Tecnológico do Amapá (IFAP), Coordenador do Curso técnico em Química (IFAP).

${ }^{3}$ Químico, Mestre em Química (UFPA), Professor e pesquisador do Curso de Licenciatura em Química do Instituto de Ensino Básico, Técnico e Tecnológico do Amapá (IFAP).

${ }^{4}$ Biomédica, Doutora em Doenças Tropicais, Professora e pesquisadora do Curso de Medicina do Campus Macapá, Universidade Federal do Amapá (UNIFAP).

${ }^{5}$ Teóloga, Doutora em Psicanálise Clínica. Atua há 15 anos com Metodologia Científica ( Método de Pesquisa) na Orientação de Produção Científica de Mestrandos e Doutorandos. Especialista em Pesquisas de Mercado e Pesquisas voltadas a área da Saúde. Doutoranda em Comunicação e Semiótica (PUC SP).

${ }^{6}$ Biólogo, Doutor em Doenças Tropicais, Professor e pesquisador do Curso de Educação Física da, Universidade Federal do Pará (UFPA).

${ }^{7}$ Biólogo, Doutor em Teoria e Pesquisa do Comportamento, Professor e pesquisador do Curso de Licenciatura em Química do Instituto de Ensino Básico, Técnico e Tecnológico do Amapá (IFAP) e do Programa de PósGraduação em Educação Profissional e Tecnológica (PROFEPT IFAP).

RC: 80859

Link de acesso: https://www.nucleodoconhecimento.com.br/educacao/matriz-curricular
} 
são apresentadas. O curso superior em Química, ofertado pelo Instituto Federal do Amapá, disserta, em suas diretrizes, os objetivos perante a formação profissional do estudante na instituição. O objetivo deste trabalho foi comparar o conteúdo de química do Exame Nacional do Desempenho dos Estudantes (ENADE) com a matriz curricular do curso superior de Licenciatura em Química do Instituto Federal do Amapá (IFAP) nos anos de 2011, 2014 e 2017. A avaliação do ENADE para licenciados em química requer que o profissional formado tenha conhecimentos dos conteúdos específicos, como é esperado. Porém ela procura neles um conhecimento que abrange a dinâmica de uma sala de aula. Baseado nisto nota-se uma predileção por determinados assuntos específicos e não específicos, buscando informações sobre a formação prática dos discentes. O curso de Licenciatura em Química do IFAP parece ter carga horária mais do que suficiente para que o discente possa se preparar e ter um bom desempenho no ENADE.

Palavras-chave: Matriz Curricular, ENADE, Licenciatura, Química.

\section{INTRODUÇÃO}

Matriz curricular é o conjunto de componentes curriculares (disciplinas) que garante o conteúdo necessário a formação de um discente em um curso. Esses componentes irão englobar as matérias obrigatórias e as não obrigatórias. Apoiada no PDI (Plano de Desenvolvimento Institucional) e no PPC (Projeto Pedagógico de Curso) estrutura o currículo com base nos estágios curriculares e extracurriculares, aulas de laboratório prático (se houver), monitoria, trabalho de conclusão de curso, atividades complementares e o perfil desejado do discente que já finalizou o curso e está no mercado de trabalho (egresso) (Carneiro et al., 2017).

A matriz curricular sofre constantes alterações em razão da velocidade com que as inovações acadêmico-tecnológicas são apresentadas, trazendo a necessidade de mudanças no currículo para garantir maior aprendizado no curso, assegurando que os estudantes possam ser mais hábeis e aptos para o mercado de trabalho (Carneiro et al., 2017). 
O curso superior em Química, ofertado pelo Instituto Federal do Amapá, disserta, em suas diretrizes, os objetivos perante a formação profissional do estudante na instituição. Serão proporcionados conhecimentos tecnológicos e científicos, em conjunto com as fundamentações teórico-práticas em todos os setores específicos da área de química, contribuindo para a formação de um profissional qualificado para assim, futuramente, atuar como professor de química na educação básica, com um foco maior no ensino médio (Ifap, 2011).

O Exame Nacional de Desempenho de Estudantes (ENADE) é um exame aplicado ao final do curso superior para medir o conhecimento dos concluintes de cada curso. Este será dividido em duas partes, a geral, executada por todos os cursos de um determinado ano, medindo habilidades cognitivas como interpretação de gráficos, raciocínio lógico e outros; e a parte específica para cada curso, medindo os conhecimentos particulares. (Wainer e Melguizo, 2018). O exame é feito num ciclo de três em três anos e sua aplicação é obrigatória (Lima et al., 2019).

É habilitado a fazer a prova todo aquele que apresentar conclusão de setenta e cinco por cento ou mais da carga horária mínima do curso, em concordância com o que é prescrito para os concluintes dos cursos superiores de Tecnologia. A inscrição desse participante deve ser feita pela Instituição de Educação Superior (IES), conforme § 60 do art. 5ำ da Lei 10.861/2004 O participante inscrito deve comparecer de forma obrigatória no local da prova, sua ausência, sem justificativa plausível, trará irregularidades ao histórico escolar, como também a emissão do diploma de conclusão de curso (Enade, 2020).

\section{OBJETIVOS}

Comparar o conteúdo de química do Exame Nacional do Desempenho dos Estudantes (ENADE) com a matriz curricular do curso superior de Licenciatura em Química do Instituto Federal do Amapá (IFAP) nos anos de 2011, 2014 e 2017. 


\section{MATERIAL E MÉTODOS}

A pesquisa foi realizada utilizando questões do Exame Nacional de Desempenho dos Estudantes (ENADE) retiradas da rede mundial de computadores, utilizando a ferramenta de busca Google (http://inep.gov.br/educacao-superior/enade/provas-egabaritos) (Inep, 2020). Foi selecionada a disciplina de Química Licenciatura e os anos 20112014 e 2017, utilizando a caixa (com o ano) disponível no site. Posteriormente fez-se uma comparação entre estas e o conteúdo programático do curso Licenciatura em Química do Instituto Federal do Amapá, IFAP (https://www.ifap.edu.br/) (Ifap, 2011). A pesquisa bibliográfica foi realizada em artigos científicos, em home office. Os dados foram compilados no aplicativo Excel, componente do pacote Office da Microsoft Corporation.

\section{RESULTADOS}

As questões de química do ENADE de 2011, 2014 e 2017 por tipo de conteúdo de cada questão estão demonstradas na figura 1. Questões que contém apenas um tipo de conteúdo (conteúdos simples) representam 30 das 90 questões das provas dos três anos (33.33\%). As questões que comtemplam mais de um conteúdo (conteúdos sobrepostos) são 60 das 90 questões (66.67\%). 
Figura 1 - Mostra a quantidade de questões de química do ENADE de 2011, 2014 e 2017 por tipo de conteúdo de cada questão.

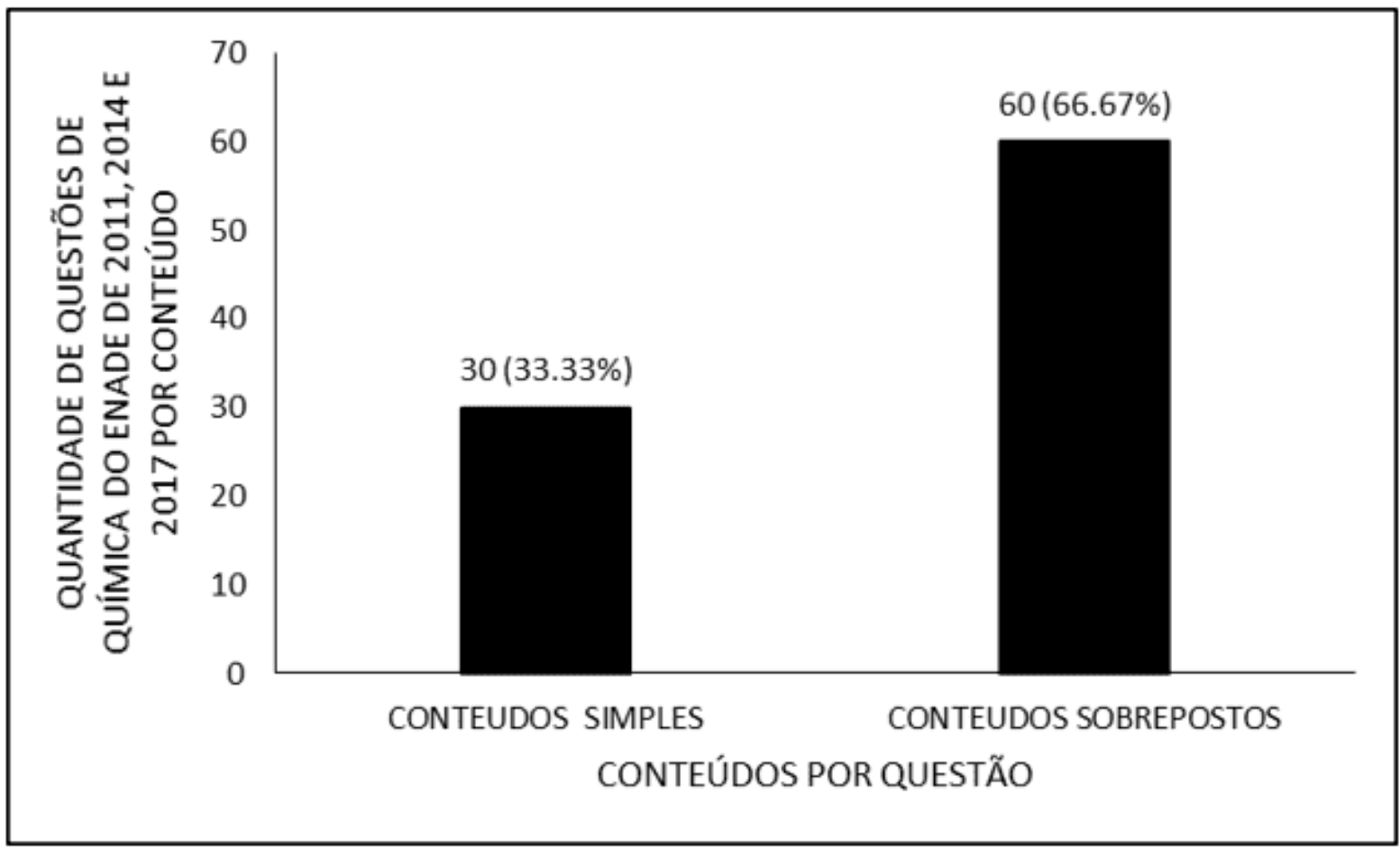

A tabela 1 mostra a distribuição (quantidade e porcentagem) das questões nos conteúdos (simples e sobrepostos) presentes no ENADE de 2011, 2014 e 2017, por questão. Entre as questões com conteúdo simples, 10 conteúdos não foram cobrados nas avaliações destes anos (1.11\%); cinco conteúdos apareceram uma vez (2.22\%); um conteúdo (Compostos orgânicos: reações e mecanismos; macromoléculas naturais e sintéticas) foi cobrado em três questões (3.33\%); e um outro (As políticas públicas e suas implicações para o ensino de Química) foi cobrado sete vezes $(7,78 \%)$. Entre os conteúdos sobrepostos o que esteve mais presente, em três questões (3.33\%), foi "Projetos e propostas curriculares no ensino de Química + Estratégias de ensino e de avaliação em Química e suas relações com as diferentes concepções de ensino e aprendizagem + Recursos didáticos para o ensino de Química". As outras combinações aprecem uma em cada questão. 
Tabela 1 - Mostra a distribuição (quantidade e porcentagem) das questões nos conteúdos (simples e sobrepostos) presentes no ENADE de 2011, 2014 e 2017, por questão.

\begin{tabular}{|c|c|c|}
\hline CONTEÚDOS SIMPLES & $\begin{array}{l}\text { Quantidade } \\
\text { de questőes }\end{array}$ & $\begin{array}{l}\text { Porcentagem } \\
\text { de questôes }\end{array}$ \\
\hline Elementos químicos (química in orgânica) & 0 & $0.00 \%$ \\
\hline Estrutura molecular (química inorgânica) & 0 & $0.00 \%$ \\
\hline Estudo de substâncias e transformações químicas (físico-quimica) & 0 & $0.00 \%$ \\
\hline Méto dos de análise em química: caracterização e quantificação & 0 & $0.00 \%$ \\
\hline Gases (química geral) & 0 & $0.00 \%$ \\
\hline Compostos inorgânicos de elementos representativos e de coordenação & 0 & $0.00 \%$ \\
\hline Bioquímica: estrutura de biomoléculas, biossíntese e metabolismo & 0 & $0.00 \%$ \\
\hline $\begin{array}{c}\text { Estratégias de ensino e de avaliação em Química e suas relações com as diferentes concepções de } \\
\text { ensino e aprend izagem }\end{array}$ & 0 & $0.00 \%$ \\
\hline Estrutura molecular e de sólidos iônicos e metálicos & 0 & $0.00 \%$ \\
\hline Compostos orgânicos + bioquímica & 0 & $0.00 \%$ \\
\hline Estrutura atômica (química geral) & 1 & $1.11 \%$ \\
\hline Química ambiental & 1 & $1.11 \%$ \\
\hline $\begin{array}{l}\text { A história da Química no contexto do desenvolvimento científico e tecnológico e a sua relação com o } \\
\text { ensino de Química }\end{array}$ & 1 & $1.11 \%$ \\
\hline Recursos didáticos para o ensino de Química & 1 & $1.11 \%$ \\
\hline Relaçôes entre ciência, tecnologia, sociedade e ambiente no ensino de Química & 1 & $1.11 \%$ \\
\hline Estad os dispersos: soluções e sistemas coloidais & 2 & $2.22 \%$ \\
\hline Termodinâmica (química geral) & 2 & $2.22 \%$ \\
\hline cinética química (química geral) & 2 & $2.22 \%$ \\
\hline $\begin{array}{c}\text { Normas de segurança e operações de laboratório utilizadas em síntese, purificação, caracte rização e } \\
\text { quantificação de substâncias e em determinações físico-químicas }\end{array}$ & 2 & $2.22 \%$ \\
\hline Projetos e propostas curriculares no ensino de Química & 2 & $2.22 \%$ \\
\hline A experimentação no ensino de Química & 2 & $2.22 \%$ \\
\hline Eletroquímica (química geral) & 3 & $3.33 \%$ \\
\hline Compostos orgânicos: reações e mecanismos; macromoléculas natu rais e sintéticas & 3 & $3.33 \%$ \\
\hline As políticas pú blicas e suas implicações para o ensino de Química & 7 & $7.78 \%$ \\
\hline TOTAL & 30 & $33.33 \%$ \\
\hline
\end{tabular}

RC: 80859

Link de acesso: https://www.nucleodoconhecimento.com.br/educacao/matriz-curricular 
CONTEÚDOS SOBREPOSTOS

Quantidade Porcentagem

\begin{tabular}{|c|c|c|}
\hline CONTEÚDOS SOBREPOSTOS & $\begin{array}{l}\text { Quantidade } \\
\text { de questōes }\end{array}$ & $\begin{array}{l}\text { Porcentagem } \\
\text { de questð̄es }\end{array}$ \\
\hline $\begin{array}{c}\text { Métodos de análise em química: caracterização e quantificação + Compostos orgânicos: reaçōes e } \\
\text { mecanismos; macromoléculas naturais e sintéticas + Bioquímica: estrutura de biomoléculas, } \\
\text { biossíntese e metabolismo + Química ambiental }\end{array}$ & 1 & $1.11 \%$ \\
\hline $\begin{array}{l}\text { Elementos químicos (química inorgânica) + Estrutura atômica (química geral) + Estrutura molecular } \\
\text { (química inorgânica) + Compostos inorgânicos de elementos representativos e de coordenaçăo + } \\
\text { Compostos orgânicos: reaçōes e mecanismos; macromoléculas naturais e sintéticas }\end{array}$ & 1 & $1.11 \%$ \\
\hline $\begin{array}{l}\text { Elementos químicos (química inorgânica) + Estudo de substâncias e transformaçōes químicas (físico- } \\
\qquad \text { química) + Gases (química geral) + Eletroquímica (química geral) }\end{array}$ & 1 & $1.11 \%$ \\
\hline \begin{tabular}{|c|}
$\begin{array}{c}\text { Estrutura atômica (química geral) + Estrutura molecular (química inorgânica) + Compostos inorgânicos } \\
\text { de elementos representativos e de coordenaçăo + Estrutura molecular e de sólidos iônicos e metálicos } \\
\text { + Elementos químicos (química inorgânica) }\end{array}$
\end{tabular} & 1 & $1.11 \%$ \\
\hline \begin{tabular}{|c|} 
Elementos químicos (química inorgânica) + Estrutura atômica (química geral) + Eletroquímica (química \\
geral) + A história da Química no contexto do desenvolvimento científico e tecnológico e a sua relaçăo \\
como ensino de Química + Estrutura molecular e de sólidos iônicos e metálicos
\end{tabular} & 1 & $1.11 \%$ \\
\hline $\begin{array}{l}\text { Compostos orgânicos: reaç̄es e mecanismos; macromoléculas + Bioquímica: estrutura de } \\
\text { biomoléculas, biossíntese e metabolismo + Compostos orgânicos + bioquímica }\end{array}$ & 1 & $1.11 \%$ \\
\hline $\begin{array}{l}\text { Compostos ongânicos: reações e mecanismos; macromoléculas naturais e sintéticas + Bioquímica: } \\
\text { estrutura de biomoléculas, biossíntese e metabolismo + Compostos orgânicos + bioquímica }\end{array}$ & 1 & $1.11 \%$ \\
\hline $\begin{array}{l}\text { Elementos químicos (química inorgânica) +Estrutura molecular (química inorgânica) + Métodos de } \\
\text { análise em química: caracterizaçăo e quantificaçăo + Compostos inorgânicos de elementos } \\
\text { representativos e de coordenaçăo + Estrutura molecular e de sólidos iônicos e metálicos }\end{array}$ & 1 & $1.11 \%$ \\
\hline $\begin{array}{c}\text { Métodos de análise em química: caracterizaçăo e quantificaçăo + Química ambiental + Estudo de } \\
\text { substâncias e transformaços químicas (físico-química) }\end{array}$ & 1 & $1.11 \%$ \\
\hline \begin{tabular}{|c|} 
Estudo de substâncias e transformaçōes químicas (físico-química) + cinética química (química geral) + \\
Eletroquímica (química geral) + Compostos orgânicos: reaçōes e mecanismos; macromoléculas naturais \\
e sintéticas + Bioquímica: estrutura de biomoléculas, biossíntese e metabolismo + Compostos \\
orgânicos + bioquímica
\end{tabular} & 1 & $1.11 \%$ \\
\hline $\begin{array}{l}\text { Elementos químicos (química inorgânica) + Estudo de substâncias e transformações químicas (físico- } \\
\text { química) + Métodos de análise em química: caracterizaçăo e quantificaçăo + Química ambiental + A } \\
\text { experimentaçāo no ensino de Química }\end{array}$ & 1 & $1.11 \%$ \\
\hline $\begin{array}{c}\text { Projetos e propostas curriculares no ensino de Química + As políticas públicas e suas implicaçōes para o } \\
\text { ensino de Química }\end{array}$ & 1 & $1.11 \%$ \\
\hline $\begin{array}{c}\text { Projetos e propostas curriculares no ensino de Química + Estratégias de ensino e de avaliaçăo em } \\
\text { Química e suas relaçōes com as diferentes concepções de ensino e aprendizagem + Recursos didáticos } \\
\text { para o ensino de Química }\end{array}$ & 1 & $1.11 \%$ \\
\hline $\begin{array}{c}\text { Projetos e propostas curriculares no ensino de Química + Recursos didáticos para o ensino de Química + } \\
\text { As políticas públicas e suas implicaçōes para o ensino de Química }\end{array}$ & 1 & $1.11 \%$ \\
\hline $\begin{array}{l}\text { Projetos e propostas curriculares no ensino de Química + Relações entre ciência, tecnologia, sociedade } \\
\text { e ambiente no ensino de Química + A experimentação no ensino de Química + As políticas públicas e } \\
\text { suas implicaçōes para o ensino de Química }\end{array}$ & 1 & $1.11 \%$ \\
\hline $\begin{array}{c}\text { Projetos e propostas curriculares no ensino de Química + As políticas públicas e suas implicaçōes para o } \\
\text { ensino de Química }\end{array}$ & 1 & $1.11 \%$ \\
\hline
\end{tabular}




\begin{tabular}{|c|c|c|}
\hline CONTEÚDOS SOBREPOSTOS & $\begin{array}{l}\text { Quantidade } \\
\text { de questŏes }\end{array}$ & $\begin{array}{l}\text { Porcentagem } \\
\text { de questões }\end{array}$ \\
\hline $\begin{array}{l}\text { Estrutura atômica (química geral) + Eletroquímica (química geral) + A história da Química no contexto do } \\
\text { desenvolvimento científico e tecnológico e a sua relação com o ensino de Química + Relações entre } \\
\text { ciência, tecnologia, sociedade e ambiente no ensino de Química }\end{array}$ & 1 & $1.11 \%$ \\
\hline $\begin{array}{l}\text { Métodos de análise em química: caracterização e quantificação + Química ambiental + Relações entre } \\
\text { ciência, tecnologia, sociedade e ambiente no ensino de Química + As políticas públicas e suas } \\
\text { implicações para o ensino de Química }\end{array}$ & 1 & $1.11 \%$ \\
\hline $\begin{array}{c}\text { Elementos químicos (química inorgânica) + Estrutura atômica (química geral) + Estrutura molecular } \\
\text { (química inorgânica) + Métodos de análise em química: caracterização e quantificação + Compostos } \\
\text { orgânicos: reações e mecanismos; macromoléculas naturais e sintéticas + Bioquímica: estrutura de } \\
\text { biomoléculas, biossíntese e metabolismo + Compostos orgânicos + bioquímica }\end{array}$ & 1 & $1.11 \%$ \\
\hline $\begin{array}{l}\text { Elementos químicos (química inorgânica) + Estrutura atômica (química geral) + Estrutura molecular } \\
\text { (química inorgânica) + Métodos de análise em química: caracte rização e quantificação + Compostos } \\
\text { inorgânicos de elementos representativos e de coordenação + Estratégias de ensino e de avaliação em } \\
\text { Química e suas relações com as dife rentes concepções de ensino e aprendizagem + Recursos didáticos } \\
\text { para o ensino de Química + A experimentação no ensino de Química }\end{array}$ & 1 & $1.11 \%$ \\
\hline $\begin{array}{c}\text { Estudo de substâncias e transformações químicas (físico-química) + Termodinâmica (química geral) + } \\
\text { Eletroquímica (química geral) }\end{array}$ & 1 & $1.11 \%$ \\
\hline $\begin{array}{l}\text { Métodos de análise em química: caracterização e quantificação + Estados dispersos: soluções e } \\
\qquad \text { sistemas coloidais + Química ambiental }\end{array}$ & 1 & $1.11 \%$ \\
\hline Estudo de substâncias e transformações químicas (físico-química) + Gases (química geral) & 1 & $1.11 \%$ \\
\hline $\begin{array}{c}\text { Elementos químicos (química inorgânica) + Estrutura molecular (química inorgânica) + Compostos } \\
\text { inorgânicos de elementos representativos e de coordenação + Estrutura molecular e de sólidos iônicos } \\
\text { e metálicos }\end{array}$ & 1 & $1.11 \%$ \\
\hline Estudo de substâncias e transformações químicas (físico-química) + Termodinâmica (química geral) & 1 & $1.11 \%$ \\
\hline $\begin{array}{c}\text { Estados dispersos: soluções e sistemas coloidais + Estratégias de ensino e de avaliação em Química e } \\
\text { suas relações com as diferentes concepções de ensino e aprendizagem + Recursos didáticos para o } \\
\text { ensino de Química + A experimentação no ensino de Química }\end{array}$ & 1 & $1.11 \%$ \\
\hline Métodos de análise em química: caracterização e quantificação + Química ambiental & 1 & $1.11 \%$ \\
\hline $\begin{array}{l}\text { Estrutura molecular (química inorgânica) + Métodos de análise em química: caracterização e } \\
\text { quantificação + Compostos orgânicos: reações e mecanismos; macromoléculas naturais e sintéticas }\end{array}$ & 1 & $1.11 \%$ \\
\hline $\begin{array}{l}\text { Estudo de substâncias e transformações químicas (físico-química) + Métodos de análise em química: } \\
\text { caracterização e quantificação + Química ambiental }\end{array}$ & 1 & $1.11 \%$ \\
\hline
\end{tabular}




\begin{tabular}{|c|c|c|}
\hline $\begin{array}{l}\text { Compostos orgânicos: reações e mecanismos; macromoléculas naturais e sintéticas + Bioquímica: } \\
\text { estrutura de biomoléculas, biossíntese e metabolismo + Compostos orgânicos + bioquímica }\end{array}$ & 1 & $1.11 \%$ \\
\hline $\begin{array}{l}\text { Estrutura molecular (química inorgânica) + Métodos de análise em química: caracterização e } \\
\text { quantificação + Compostos orgânicos: reações e mecanismos; macromoléculas naturais e sintéticas + } \\
\text { Bioquímica: estrutura de biomoléculas, biossíntese e metabolismo + Compostos orgânicos + bioquímica }\end{array}$ & 1 & $1.11 \%$ \\
\hline $\begin{array}{l}\text { Elementos químicos (química inorgânica) + estrutura atômica (química geral) + Estrutura molecular } \\
\text { (química inorgânica) + Termodinâmica (química geral) + Compostos inorgânicos de elementos } \\
\text { representativos e de coordenação + Compostos orgânicos: reações e mecanismos; macromoléculas } \\
\text { naturais e sintéticas + Bioquímica: estrutura de biomoléculas, biossíntese e metabolismo + Estrutura } \\
\text { molecular e de sólidos iônicos e metálicos + Compostos orgânicos + bioquímica }\end{array}$ & 1 & $1.11 \%$ \\
\hline $\begin{array}{c}\text { Termodinâmica (química geral) + Compostos orgânicos: reações e mecanismos; macromoléculas } \\
\text { naturais e sintéticas }\end{array}$ & 1 & $1.11 \%$ \\
\hline $\begin{array}{c}\text { Projetos e propostas curriculares no ensino de Química + as políticas públicas e suas implicações para o } \\
\text { ensino de Química }\end{array}$ & 1 & $1.11 \%$ \\
\hline $\begin{array}{l}\text { Estratégias de ensino e de avaliação em Química e suas relações com as diferentes concepções de } \\
\text { ensino e aprendizagem + as políticas públicas e suas implicações para o ensino de Química }\end{array}$ & 1 & $1.11 \%$ \\
\hline $\begin{array}{l}\text { Projetos e propostas curriculares no ensino de Química + Estratégias de ensino e de avaliação em } \\
\text { Química e suas relações com as diferentes concepções de ensino e aprendizagem }\end{array}$ & 1 & $1.11 \%$ \\
\hline $\begin{array}{l}\text { Projetos e propostas curriculares no ensino de Química + Estratégias de ensino e de avaliação em } \\
\text { Química e suas relações com as diferentes con cepções de ensino e aprendizagem + as políticas públicas } \\
\text { e suas implicações para o ensino de Química }\end{array}$ & 1 & $1.11 \%$ \\
\hline $\begin{array}{l}\text { Estudo de substâncias e transformações químicas (físico-química) + Métodos de análise em química: } \\
\text { caracterização e quantificação + Eletroquímica (química geral) }\end{array}$ & 1 & $1.11 \%$ \\
\hline
\end{tabular}


Cinética química (química geral) + Bioquímica: estrutura de biomoléculas, biossíntese e metabolismo

Elementos químicos (química inorgânica) + Estrutura molecular (química inorgânica) + Gases (química geral) + Compostos inorgânicos de elementos representativos e de coordenação + Estrutura molecular e de sólidos iônicos e metálicos

\begin{tabular}{|c|c|c|}
\hline e de sólidos iônicos e metálicos & & \\
\hline $\begin{array}{l}\text { Estrutura molecular (química inorgânica) + Compostos orgâni cos: reações e mecanismos; } \\
\text { macromoléculas naturais e sintéticas + Compostos orgâni cos + bioquímica }\end{array}$ & 1 & $1.11 \%$ \\
\hline $\begin{array}{l}\text { Elementos químicos (química inorgânica) + Estrutura atômica (química geral) + Estrutura mol ecular } \\
\text { (química inorgânica) + Eletroquímica (química geral) }\end{array}$ & 1 & $1.11 \%$ \\
\hline $\begin{array}{c}\text { Estrutura atômica (química geral) + Métodos de análise em química: caracterização e quantificação + } \\
\text { Compostos inorgâni cos de elementos representativos e de coordenação + A experimentação no ensino } \\
\text { de Química }\end{array}$ & 1 & $1.11 \%$ \\
\hline $\begin{array}{c}\text { Métodos de análise em química: caracte rização e quantifi cação + A experimentação no ensino de } \\
\text { Química }\end{array}$ & 1 & $1.11 \%$ \\
\hline Termodinâmica (química geral) + Eletroquímica (química ge ral) & 1 & $1.11 \%$ \\
\hline $\begin{array}{l}\text { Estudo de substâncias e transformações químicas (físico-química) + Termodinâmica (química geral) + } \\
\text { cinética química (química geral) }\end{array}$ & 1 & $1.11 \%$ \\
\hline Cinética química (química geral) + Bioquímica: estrutura de biomolécul as, biossíntese e metabolismo & 1 & $1.11 \%$ \\
\hline Termodinâmica (química geral) + Gases (química geral) & 1 & $1.11 \%$ \\
\hline $\begin{array}{l}\text { Métodos de análise em química: caracterização e quantificação + Compostos orgânicos: reaçães e } \\
\text { mecanismos; macromoléculas naturais e sintéticas + Bioquímica: estrutura de biomoléculas, } \\
\text { biossíntese e metabolismo + Compostos orgânicos + bioquímica }\end{array}$ & 1 & $1.11 \%$ \\
\hline $\begin{array}{l}\text { Métod os de análise em química: caracterização e quantificação + cinética química (química geral) + } \\
\text { Compostos orgânicos: reações e mecanismos; macromoléculas naturais e sintéticas + A } \\
\text { experimentação no ensino de Química }\end{array}$ & 1 & $1.11 \%$ \\
\hline $\begin{array}{l}\text { Compostos orgânicos: reações e mecanismos; macromoléculas naturais e sintéticas + Bioquímica: } \\
\text { estrutura de biomoléculas, biossíntese e metabolismo + A experimentação no ensino de Química + } \\
\text { Compostos orgânicos + bioquímica }\end{array}$ & 1 & $1.11 \%$ \\
\hline $\begin{array}{l}\text { Estratégias de ensino e de avaliação em Química e suas relações com as diferentes concepções de } \\
\text { ensino e aprendizagem + Recursos didáticos para o ensino de Química }\end{array}$ & 1 & $1.11 \%$ \\
\hline $\begin{array}{c}\text { Projetos e propostas curriculares no ensino de Química + Relaçães entre ciência, tecnologia, socie dade } \\
\text { e ambiente no ensino de Química }\end{array}$ & 1 & $1.11 \%$ \\
\hline Projetos e propostas curriculares no ensino de Química + Recursos didáticos para o ensino de Química & 1 & $1.11 \%$ \\
\hline $\begin{array}{l}\text { Estudo de substâncias e transformações químicas (físico-química) + Métodos de análise em química: } \\
\text { caracterização e quantificação + Termodi nâmica (química ge ral) }\end{array}$ & 1 & $1.11 \%$ \\
\hline
\end{tabular}




\begin{tabular}{|c|c|c|}
\hline $\begin{array}{c}\text { A experimentação no ensino de Química + termodinâmica (química ge ral) + Métodos de análise em } \\
\text { quími ca: caracterização e quantificação + Estudo de substâncias e transformações químicas (físico- } \\
\text { química) }\end{array}$ & 1 & $1.11 \%$ \\
\hline $\begin{array}{c}\text { Elementos químicos (química inorgânica) + Estrutura atômica (química geral) + Estrutura molecular } \\
\text { (química inorgânica) + Estudo de substâncias e transformaçães químicas (físico-química) + Métodos de } \\
\text { análise em quími ca: caracterização e quantificação + Eletroquímica (química geral) + Estratégias de } \\
\text { ensino e de avaliação em Química e suas relações com as diferentes concepçães de ensinoe } \\
\text { aprendizagem + Estrutura molecular e de sólidos iônicos e metálicos }\end{array}$ & 1 & $1.11 \%$ \\
\hline $\begin{array}{c}\text { Projetos e propostas curriculares no ensino de Química + Estratégias de ensino e de avaliação em } \\
\text { Química e suas relações com as diferentes concepções de ensino e aprendizagem + Recursos didáticos } \\
\text { para o ensino de Química }\end{array}$ & 3 & $3.33 \%$ \\
\hline
\end{tabular}

Os conteúdos que têm maior tempo dentro da matriz do curso de graduação em licenciatura em química do Instituto Federal de Educação, Ciência e Tecnologia do Amapá (IFAP), campus Macapá, levando em conta as 400 horas em sala de cada período, é Estágio Supervisionado em Ensino em Química I. Esta disciplina tem 160 horas e representa $40 \%$ do total de horas do 60 período e $6.67 \%$ do total de horas do curso.

Em seguida aparecem Fundamentos da Química e Fundamentos Sócio-Históricos da Educação (1ำ período); Filosofia da Educação e Ética Profissional (2ำ período); Psicologia da Educação (3ำ período); Didática Geral (4ำ período); Química Analítica Quantitativa e Legislação e Políticas Públicas (5ำ período). Cada uma destas representa 80 horas de carga horária, $20 \%$ do total de horas dos seus respectivos períodos e $3.33 \%$ do total de horas do curso.

Conteúdos como Metodologia do Trabalho Cientifico e Comunicação e Linguagem (1ํㅜ período); Química Geral I, Física I, Cálculo Diferencial e Integral I e Álgebra Linear e Geometria Analítica (2º período); Química Geral II, Físico-Química I, Física II e Cálculo Diferencial e Integral II (3o período); Físico-Química II, Química Inorgânica I; Química Orgânica I; e Química Analítica Qualitativa (4º período); Química Inorgânica II e Química Orgânica II (5ำ período) representam 60 horas de carga horária, 15\% do total de horas dos seus respectivos períodos e $2.50 \%$ do total de horas do curso. 
As demais disciplinas (conteúdos) representam 40 horas de carga horária, 10\% do total de horas dos seus respectivos períodos e $1.67 \%$ do total de horas do curso (Tabela 2).

Tabela 2 Mostra a distribuição das disciplinas (conteúdos) do curso de graduação em licenciatura em química do Instituto Federal de Educação, Ciência e Tecnologia do Amapá (IFAP), campus Macapá. Cada conteúdo apresenta sua carga horária, a porcentagem dentro do período e sua porcentagem referente a totalidade do curso.

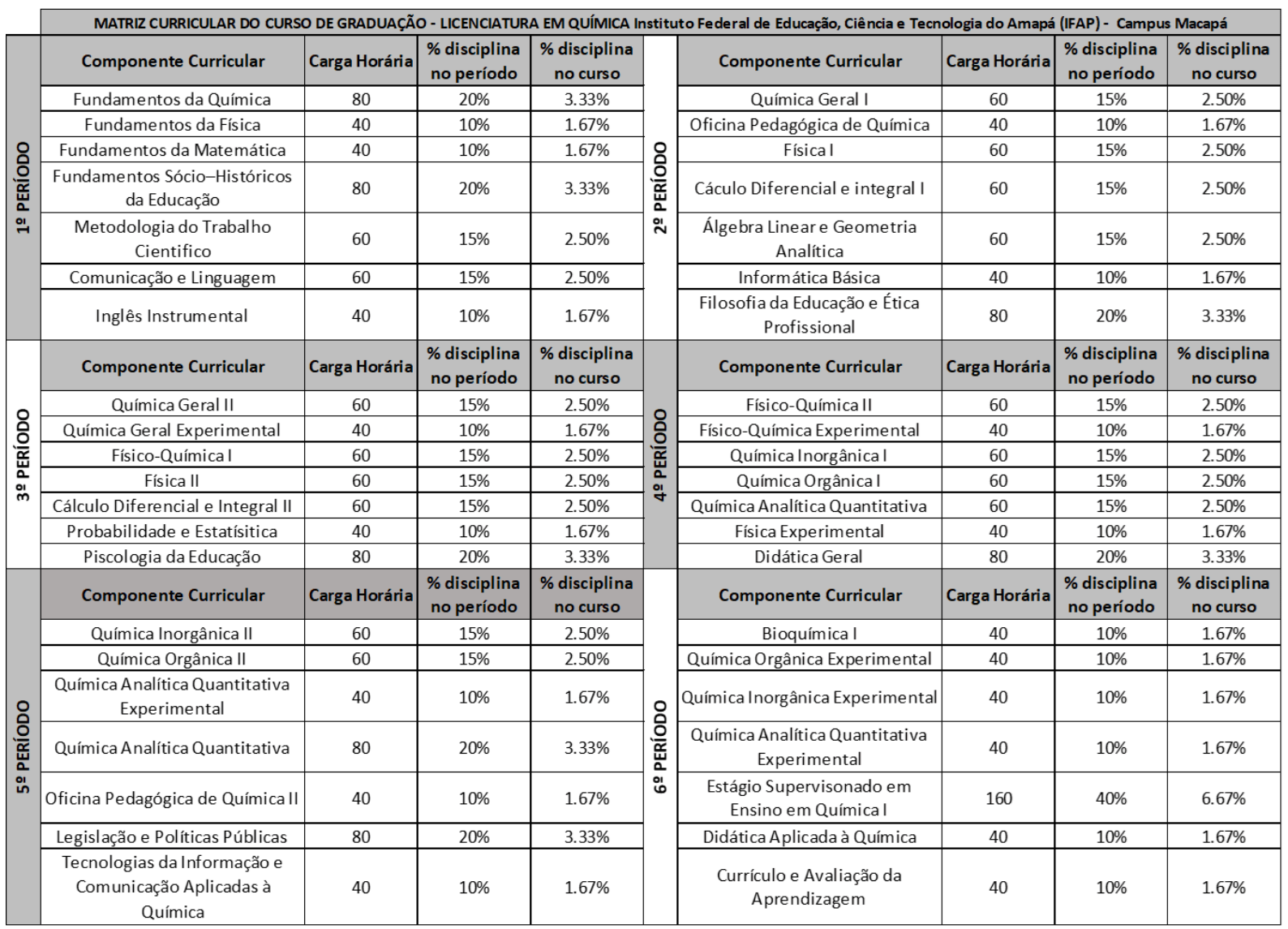

\section{DISCUSSÃo}

Nos dados apresentados na figura 1 pode-se notar uma preferência maior pelos assuntos que requerem interdisciplinaridade, isso porque essas questões necessitam de um conhecimento que integre diferentes conteúdos para serem resolvidas. Isso se torna importante pois a capacidade de conectar assuntos diversificados parece garantir um aprendizado mais sólido, e ao mesmo tempo ajuda a construir o RC: 80859

Link de acesso: https://www.nucleodoconhecimento.com.br/educacao/matriz-curricular 
conhecimento científico do indivíduo. O exame cobra do acadêmico a junção de saberes individuais de cada matéria e de modo simultâneo o alinhamento com outras disciplinas (SOUSA et., 2017). A interdisciplinaridade de questões garante que o acadêmico interprete os problemas ligando-as com o cotidiano, permitindo a interrelação do conhecimento em diferentes áreas (Coelho e Scremin, 2019; Carmo et al., 2021; Gortz et al., 2021).

O ENADE se preocupa em que o discente formado em um curso superior de química compreenda a leis que regem o ensino desta disciplina, e como estas normas afetam este ensino (tabela1). A formação de um profissional crítico e conhecedor das normas e da realidade educacional de onde atua pode fazer com que, no futuro, esse professor contribua com melhorias significativas nos métodos de ensino da química, fazendo com que a taxa de conhecimento aumente junto com a melhoria da vida dos estudantes (Pontes et al., 2008).

A outra preocupação presente nos exames analisados foi com a composição orgânica dos seres vivos (tabela1). As reações químicas fazem com que as células funcionem, portanto se um professor de química conhecer o funcionamento celular conseguirá explicar a função das moléculas orgânicas de maneira mais próxima ao cotidiano dos discentes (Leite e Velani, 2019). Colocar o conteúdo na perspectiva do dia a dia dos estudantes auxilia a compreensão destas moléculas e seus processos (Hipólito e Silveira, 2011; Silveira et al., 2014).

Ainda na tabela 1, 3.33\% das questões sobrepostas estão ligadas ao conhecimento de concepção de projetos, estratégias de ensino e avaliação em química. A formação profissional no curso superior em licenciatura tende a integrar conhecimentos acadêmicos a outros mais específicos do conteúdo de química. A participação dos docentes em formação, ainda durante o curso superior, em estágios supervisionados e em programas de iniciação científica promovidos pela federação parecem contribuir significativamente no conteúdo crítico e acadêmico destes. Isso aprimoraria as características cobradas nestas questões (Rosa et al., 2018). 
Os dados mostram que os principais conteúdos cobrados no ENDADE, no período, foram políticas públicas, composição orgânica dos seres vivos, concepção de projetos, estratégias de ensino e avaliação em química (tabela 1). A matriz curricular do curso de licenciatura em química do IFAP parece comtemplar estes conhecimentos (tabela2). Estágio supervisionado, didática geral e legislação e políticas públicas correspondem a 13\% (400 horas) do total de horas do curso. Química orgânica I e II tem juntas 160 horas e são $5 \%$ do total de horas do curso. Assim a Plano Pedagógico de Curso (PPC), como foi pensado pelo colegiado da instituição onde se encontra, está em consonância com as mudanças na legislação federal que regem a formação de docentes em cursos de licenciatura. $\mathrm{O}$ curso analisado respeita regionalidades e isso reflete no tipo de formação dos seus discentes (Santos et al., 2020).

\section{CONCLUSÃO}

A avaliação do ENADE para licenciados em química requer que o profissional formado tenha conhecimentos dos conteúdos específicos (como química orgânica, por exemplo) como é esperado. Porém ela procura neles um conhecimento que abrange a dinâmica de uma sala de aula (quanto ao tipo de aula, avaliação, como pensar uma matriz curricular, como contribuir com mudanças para melhoria do ensino, como avaliar um conteúdo). Baseado nisto nota-se uma predileção por determinados assuntos específicos e não específicos, buscando informações sobre a formação prática dos discentes

O curso de Licenciatura em Química do Instituto Federal do Amapá, IFAP, parece ter carga horária mais do que suficiente para que o discente possa se preparar e ter um bom desempenho no ENADE, pois segue, com melhorias, o que rege a norma federal para este tipo de curso.

\section{REFERÊNCIAS}

CARMO, D. R. D. et al. A física no enem e no curso técnico de química do instituto federal do amapá (IFAP): Uma comparação curricular. Revista Científica 
Multidisciplinar Núcleo do Conhecimento, v. 3, p. 80-88, 2021. Disponível em: < https://www.nucleodoconhecimento.com.br/educacao/fisica-no-enem >.

CARNEIRO, J. D. et al. Matriz Curricular para Cursos de Ciências Contábeis. Brasilia DF: Fundação Brasileira de Contabilidade, 2017. 208p.

COELHO, F. B. O.; SCREMIN, G. A Interdisciplinaridade nas Licenciaturas em Ciências da Natureza: Análise de Projetos Pedagógicos de Cursos. XII Encontro Nacional de Pesquisa em Educação em Ciências - XII ENPEC Natal, RN: Universidade Federal do Rio Grande do Norte 2019.

ENADE. Antes da Prova, 2020. Brasilia DF, 2020. Disponível em: < https://www.gov.br/inep/pt-br/acesso-a-informacao/perguntas-frequentes/examenacional-de-desempenho-dos-estudantes-enade >. Acesso em: 02 fev 2021.

GORTZ, J. S. et al. Química do ensino médio técnico e enem: Uma comparação curricular. Revista Científica Multidisciplinar Núcleo do Conhecimento, v. 3, p. 8999 , 2021.

Disponível em: https://www.nucleodoconhecimento.com.br/educacao/comparacao-curricular >.

HIPÓLITO, A. F.; SILVEIRA, H. E. D. As questões de Química do Exame Nacional do Ensino Médio (ENEM) em um enfoque transversal e interdisciplinar. 2011. Disponível em: < http://abrapecnet.org.br/atas_enpec/viiienpec/resumos/R0237-1.pdf >. Acesso em: 11 fev 2021.

IFAP. PPC Licenciatura em Química. Macapá AP, 2011. Disponível em: < https://macapa.ifap.edu.br/index.php/mais-noticias/395-licenciatura-em-quimica >. Acesso em: 02 fev 2021.

INEP. Provas e Gabaritos ENADE, 2020. Brasilia DF, 2020. Disponível em: < http://inep.gov.br/educacao-superior/enade/provas-e-gabaritos >. Acesso em: 14 jul 2020. 
LEITE, K. D. C.; VELANI, V. Divertindo-se com a química: o ensino e a aprendizagem por meio do lúdico. Braz. J. of Develop., v. 5, n. 11, p. 25115-25133, 2019.

LIMA, P. D. S. N. et al. Análise de dados do Enade e Enem: uma revisão sistemática da literatura. Avaliação (Campinas), v. 24, n. 1, p. 89-107, 2019.

PONTES, A. N. et al. O Ensino de Química no Nível Médio: Um Olhar a Respeito da Motivação. XIV Encontro Nacional de Ensino de Química (XIV ENEQ) Curitiba PR: Universidade Federal do Paraná 2008.

ROSA, D. L.; MENDES, A. N. F.; LOCATELLI, A. B. A formação da identidade docente na licenciatura em química e suas relações com a aprendizagem significativa a partir da análise do Modelo de Ensino de Gowin. Revista Práxis, v. 10, n. 20, dez., 2018, v. $10, \quad$ n. $20, \quad$ p. $1-14,2018$. Disponível em: < http://revistas.unifoa.edu.br/index.php/praxis/article/view/830/2237 >.

SANTOS, D. R. C. M. D.; LIMA, L. P.; JUNIOR, G. G. A formação de professores de química, mudanças na regulamentação e os impactos na estrutura em cursos de licenciatura em química. Quim. Nova, v. 43, n. 7, p. 977-986, 2020. Disponível em: $<$ https://www.scielo.br/pdf/qn/v43n7/0100-4042-qn-43-07-0977.pdf >.

SILVEIRA, F. L.; STILCK, J.; BARBOSA, M. Comunicações: Manifesto sobre a qualidade das questões de Física na Prova de Ciências da natureza no Exame Nacional de Ensino Médio. Caderno Brasileiro de Ensino de Física, v. 31, n. 2, p. 473-479, 2014.

WAINER, J.; MELGUIZO, T. Políticas de inclusão no ensino superior: avaliação do desempenho dos alunos baseado no Enade de 2012 a 2014. Educ. Pesqui., v. 44, p. e162807, 2018.

Enviado: Março, 2021.

Aprovado: Março, 2021 